\title{
The Insights on Perceived Price-Quality
}

\author{
Ignasius Heri Satrya Wangsa \\ University of Saint La Salle (USLS) - Phillipines
}

\begin{tabular}{l|l}
\hline A R T I C L E IN F O & A B S T R A C T \\
\hline $\begin{array}{l}\text { Received: April 10, 2011 } \\
\text { Final revision: September 16, 2011 }\end{array}$ & $\begin{array}{l}\text { This research employs four theories; absolute and relative price diffe- } \\
\text { rences (Theory-1), a "free" product (Theory-2), consumer perception } \\
\text { of price unfairness (Theory-3), and consumer perception of price as an } \\
\text { Keywords: } \\
\text { indicator of product quality (Theory-4). All of these are integrated and } \\
\text { synthesizal in order to applicable provide an interpretation framework. } \\
\text { Using Consistency Test and phenomenological approach, the author } \\
\text { analyzes the participants' responses around the issues of price and } \\
\text { benefit to get some insights on perceived price-quality. }\end{array}$ \\
\end{tabular}

$\mathrm{P}$ erceived price-quality or perceived pricequality relationship is price perception on expectation of highest benefit which is manifested in consumers' interpretation on relationship between price and product quality.

There was time when market seemed to be aggresive with the coming of low-priced products. People were rushing to buy for no reason. In this case perceived price-quality is followed by consumers' quick process of decision making to give positive response. In quick process of decision making, there is a very little search and decision effort.
Different products may determine different degree of perceived price-quality. Some can be purchased quickly with very little mental effort, but the others require slow process of buying decision in which a consumer needs moderate amount of time for information gathering and deliberation.

Some years back in Indonesia there was a great demand of cheap motorbikes from China. People were so enthusiastic to welcome them. In most south-east Asian countries such as Indonesia, Singapore, Malaysia and the Philippines market penetration of low-priced Chinese products are still significant. Everyday low price policy in budget 
airline industry offering domestic or international flight shows another fact that low-priced product is not about giving less benefit but reasonable benefit. This reflects a great demand of low-priced product which might configure a reality that price itself can play consumers' emotion. It is not abou product consumption but price consumption Price has become object of consumption.

It was noted in the history that since the invention of information technology life has been very busy with gadget. Suddenly, there is a necessary need of connectivity, and market reactively responds with high demand of low-priced digital products. Nowadays, it is very common to know people in all social class use cellphone in their daily life. Suddenly, cheap products are found everywhere even the pirated version could easily be found in the market. It is always coming with price that contributes to consumers' dynamics on perceived price-quality.

Price can effectively play emotion of the market. Within this context price sensitive market is not merely dealing with buying power. People tend to strongly respond change of price in the market which is caused by perception of product quality. Those who crave for luxury consumption or prestige-seeking consumers may prefer to sacrifice their resources -- to pay more rather than to choose product with lower or cheaper price because high price refers to high quality.

For consumer, price is an easy means of product measurement. It is concrete and consumers trus price much more than their own evaluation of product worth (Shapiro in Bedeian 1971). Research in perceived price-quality might be beneficial to know degree of consumer satisfaction, in other words, degree of consumers' well-being. As price perception on quality is related with belie -- the expenditure of money as being similar to the expenditure of effort, the more effort means the more a consumer spends on a high-priced product which means also he is going to the highest degree of his well-being. However, this should happen when consumers are aware while making decision specially in price reinforcement environment.

There is an area which needs to be considered as consumer limitation. Very often consumers are emotionally authorized indirectly by price and put on their best effort for it. Contribution of ads has been very significant in reshaping image of price ie. the relationship between price and product so that price itself has become dominant or "product" in consumers' mindset. Price has been taken as the most valid representation to value product. Study by McConnell and Stafford and Enis (Bedeian 1971:64) reveals that emotional perception toward price and product quality may happen because consumers are trying to rationalize relationship between price and such things as the physical characteristics of a product, brand name and packaging. The abstract form of price has been brought into being more physical representation.

This research is aimed to explore findings related with perceived price-quality. In addition, this research shall reveal some basic theoretical pillars and give general idea for further perceived pricequality research. Findings may also be used to bring out issues on consumer limitation dealing with perceived price-quality. From this perspective firms may gain informative values and invaluable insights to reshape their competitiveness without lacking their sense of social responsibility.

\section{Theoretical review}

To support analyzing perceived price-quality four theories are employed namely Theory-1: Absolute price differences and relative price differences or partial relative thinking (Azar 2009), Theory-2: A "free product" (Anderson 2009), Theory-3: Consumer perception of price unfairness (Bolton et al. 2003), and Theory-4: Consumer perception of price as an indicator of product quality (Bedeian 1971). The above four theories are chosen with the assumption that perceived price-quality most likely happens in price sensitive consumers (Theory-1), trend of free products as promotional gimmick (Theory-2), the risk to experience wrong buying (Theory-3), and trend of unfamiliar brands in a familiar product category where price as common indicator for product quality (Theory-4). Those four theories are integrated and synchronized for

\begin{tabular}{|c|c|c|}
\hline THEORY-1 & WHEN PRICE IS LOWER & \multirow{3}{*}{$\begin{array}{l}\text { PERCEIVED } \\
\text { PRICE-QUALITY } \\
\text { CONTEXT } \\
\text { Perceived price-quality } \\
\text { happens as consumers are } \\
\text { looking for low-price } \\
\text { product with high quality. } \\
\text { Consumers employ absolute } \\
\text { and relative price differences } \\
\text { to make more saving. }\end{array}$} \\
\hline $\begin{array}{l}\text { Absolute price differences } \\
\text { and relative price } \\
\text { differences } \\
\text { Or partial relative thinking } \\
\text { (Azar 2009) }\end{array}$ & $\begin{array}{l}\text { Consumer tends to make more } \\
\text { effort to save a certain absolute } \\
\text { amount when the good's price is } \\
\text { lower, because relative to the good's } \\
\text { price the savings seem larger. }\end{array}$ & \\
\hline & & \\
\hline
\end{tabular}

Exhibit 1: Conceptual Model - 1

\begin{tabular}{|c|c|c|}
\hline THEORY-2 & $\begin{array}{l}\text { WHEN THERE IS "FREE" } \\
\text { OR NO PRICE }\end{array}$ & $\begin{array}{c}\text { PERCEIVED } \\
\text { PRICE-QUALITY CONTEXT }\end{array}$ \\
\hline $\begin{array}{l}\text { A "free product" } \\
\text { (Anderson 2009) }\end{array}$ & $\begin{array}{l}\text { "There is no such thing as a free } \\
\text { lunch." A free-lunch counter is a } \\
\text { great leveler of classes, and when a } \\
\text { man takes a position before one of } \\
\text { them he must give up all hope of } \\
\text { appearing dignified. "Free" is just a } \\
\text { "free sample" intended both } \\
\text { introduce a product and trigger a } \\
\text { slight feelling of moral debt that may } \\
\text { encourage to buy full-price item. }\end{array}$ & $\begin{array}{l}\text { perceived price-quality } \\
\text { happens when the price is } \\
\text { decreasing with expectation of } \\
\text { high quality even seemingly to the } \\
\text { level of no price. It shouldn't be } \\
\text { happened reactive decision if } \\
\text { consumer fully understand the } \\
\text { meaning of free or priceless } \\
\text { unless he realizes that he should } \\
\text { give up all hope of appearing } \\
\text { dignified, or simply he may be in } \\
\text { the condition of lack of price }\end{array}$ \\
\hline
\end{tabular}

Exhibit 2: Conceptual Model - 2

\begin{tabular}{|l|l|}
\hline \multicolumn{1}{|c|}{\begin{tabular}{|l|l|}
\hline Consumer perception of \\
price unfairness \\
(Bolton et al. 2003)
\end{tabular}} & $\begin{array}{l}\text { Consumers are sensitive to several } \\
\text { reference points. When the price is } \\
\text { increasing consumers start to } \\
\text { skeptic toward price. High price is } \\
\text { considered as "inappropriate and } \\
\text { wrong". }\end{array}$ \\
\hline
\end{tabular}

Exhibit 3: Conceptual Model - 3 fomework. They are presented following four Conceptual Models (t) Exhibit-4). Proposed integration model is also presented to show the conceptual ea of perceived price-quality relationship in the ontext of Customer Perceived Value (Exhibit-5). 


\section{THEORY-4}

\begin{tabular}{|c|} 
Consumer perception of \\
price as an indicator of \\
product quality \\
(Bedeian 1971; Robin and \\
Dominguez (2008))
\end{tabular}

Dominguez (2008))

Customer tends to seek high-priced product tor expectarion of highest benefiti ie. HIGH PRICE - HIGH QUALITY(Theory-4) ie. HIGH PRICE - LOW QUALITY (Theory-3)

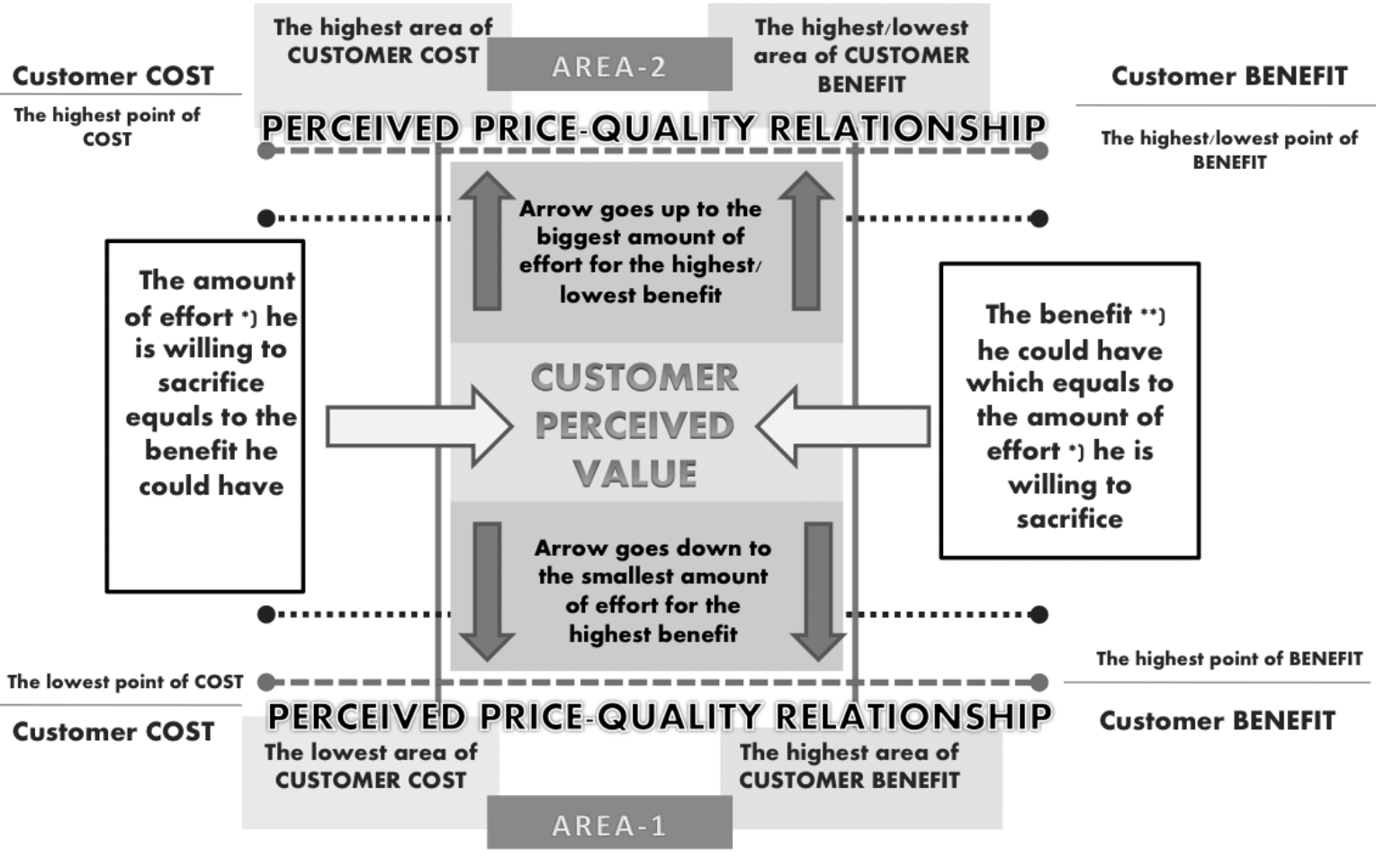

Customer tends to seek low-priced product for expectation of highest benefit ie. LOW PRICE - HIGH QUALITY (Theory-1, Theory-2)

Exhibit 5: Proposed Integration Mode

Exhibit 5: Proposed Integration Model
in Customer Perceived Value context
Price is the easiest indicator for product quality. Increasing price is easily predicted as increasing product quality or values. The most easiest way to see product quality or values is through price. From this point of view it may happen price trick which is always high price but low quality product ie. offering high-priced low quality product. Bolton et al (2003) used the term "consumer perception of price unfairness" (see Exhibit-3) as consumers are sensitive to several reference points (outside the price). In her article she exposed consumers skepticism toward high price which is inappropriate and wrong as they appear to have poor apreciation of the cost faced by the firm. Therefore, corrective intervention is needed. Perceived price-quality in this context is that highpriced product may potentially be perceived as low quality as consumers find the high price is unfair and incorrect. They experience wrong buying as the result of emotional or reactive decision which bring their perception to high-priced product but low quality. High-priced products are supposed to bring high benefit but at the end they are considered as wrong price with low benefit (Exhibit-5 Area2). Consumers in this category would always be suspicious with high-priced products. The reactive and skeptic response toward high-priced products is that their prices are unfair. The prices would direct consumers' inclination to cancel their buying decision.

Azar (2009) conducted experiment related with consumer choice. His research reveals consumer's preference between time and money which depends on the good's price. This is considered as inconsistent with the theory of rational choice. Consumers often behave partial relative thinking that they consider not only absolute price differences but also relative price differences ie. what part of the good's price they can save. This leads consumers to make more effort to save a certain absolute amount when the good's price is lower, because relative to the good's price the savings seem larger. Consumer uses his rationality as he is aware with his decision. He measures price or money with time or effort. Low price will be considered as more saving not only on money but also time. This theory may be used to explain that people are rushing to buy something because of money and time-saved orientation (Exhibit-1 or Exhibit-5 Area-1). It is the value of money as invaluable asset or resource that people start to think of saving. At the extreme point people might look irrational to buy something seemingly for no reason which is actually manifestation of high benefit ie. their money and time-saved orientation (Exhibit-5 Area-1).

Anderson (2009) described the philosophical meaning of "free product" which is actually wrong. A person cannot get something for nothing. If something appears to be free, there is always a cost to the person or to society as a whole, even though that cost may be hidden or distributed. "There is no such thing as a free lunch." A freelunch counter is a great leveler of classes, and when a man takes a position before one of then he must give up all hope of appearing dignified. "Free" is just a "free sample" intended both introduce a product and trigger a slight feeling of moral debt that may encourage to buy fullprice item. However, the perceived price-quality in this context happens as consumers are more speculative or "gambling" on low price and high quality. Some just realize that they play with giving up "all hope of appearing dignified", or simply they may be in the condition of lack of price information (Exhibit-2 and Exhibit-5 Area-2).

Robin and Dominguez (2008) show the relationship between the experience of fulfillmen and the amount of money we spend to acquire more possessions. More possessions mean more fulfillment. From this point it can be drawn that consuming high-priced product means high expenditure of money, and at the end it reflects high need of experience of fulfillment. Spending money for high-priced product is also to defend against unpleasant emotional states like fear, worry, anxiety and loneliness. Following this motive is the 
need to have high-priced products which could give highest benefit. This theory corresponds with Bedeian (1971) that high price policy might be suitable for those who are impressed with the importance of quality or products which can give highest benefit. This context acquires price as commodity. Price has become "money" which is always achieved to satisfy needs. It is not product that should satisfy needs, but it is price. (Exhibit-4 and Exhibit-5 Area-2)

\section{Research question}

How do we rationalize consumers' response around the issues of price and benefit to get insight on perceived price-quality?

\section{METHODS}

Non-probability sampling with convenience sampling method is applied. Selection of the participants is based on the author's judgement with regard to efficiency and effectivity of the research. Participants are the Third Year local college students taking Marketing Management subject and living in the Philippines. They are required to fill up questionnaire. Quantitative data from questionnaire are computed using SPSS ver. 17.0. Thereafter, output from SPSS are interpreted and analyzed on the aspect of participants' way of thinking coherently specially when they are confronted with some challenging and disturbing statements around the issue of price and benefit. The autho proposes this method as Consistency Test (CT).

There are four phases of data analysis. The autho uses Consistency Test (CT) for Phase-1 with 42 students as participants. Phase-2 is participated by 37 students, while Phase- 3 is participated by two students and conducted using phenomenological approach ie. Narrative Analysis as suggested by Colaizzi (1978) in Goulding (2004) with two basic assumptions: (1) Participants have stocks of knowledge which produce familiarity, but they are always incomplete and open-ended. This condition of incomplete and open-ended familiarity requires interpretative application; (2) A person's life is a socially constructed totality in which views and experiences interrelate coherently and meaningfully. Those views and experiences of participants can be source of data to describe the fact. Due to limited resource the author labels this approach as "semi-phenomenological" as it covers only on Narrative Analysis. Interpretation on the narratives is made using "fusion of horizons" between the author's frame of reference and the texts being interpreted (Thompson 1997; Goulding 2004). Prior to the interpretation the author applies four steps: (1) acquiring a feeling; (2) extracting main statement; (3) formulating meaning; and (4) clustering meaningful theme. In Phase-4 there are 42 participants. They were given two Situations or Contexts. Situation-1 is dealing with high price and more benefit while Situation-2 is the opposite ie. low price and less benefit. Hence, the participants are required to give response to price and benefit differences in both Situations. It took two months for data gathering from Phase-1 to Phase-4.

\section{RESULTS AND DISCUSSION}

Phase-1

In Phase-1 participants were given Questionnaire-1 and asked to make preference ie. make a choice from nine combination of relationship between price and quality: (1) high price - high quality (Choice-1); (2) high price - medium quality (Choice-2); (3) high price - low quality (Choice-3); (4) medium price - high quality (Choice-4); (5) medium price - medium quality (Choice-5); (6) medium price - low quality (Choice-6); (7) low price - high quality (Choice-7); (8) low price - medium quality (Choice-8); (9) low price low quality (Choice-9). There are also 4 (four) statements that need to be responded: (1) price always has connection with product quality (V4); (2) price is more important than product quality (V3); (3) high quality is always followed by high price (V1); (4) what I need is high quality with low price (V2). Participants are asked to respond using Likert scale 1 (=strongly disagree) to 5 (=strongly agree). Four Consistency Test (CTs) were used in Phase-1.
Consistency Test-1: Consistency test between V and V2 (see Table-1.1 to 1.6). Descriptive statistics and one-sample test to measure the consistency

between V1 (High quality is always followed by high price) and V2 (What I need is high quality with low price).

Table-1.1. Descriptive Statistics

\begin{tabular}{lccccccc}
\hline & $\mathrm{N}$ & \multicolumn{2}{c}{ Minimum } & Maximum & Mean & Std. Deviation & \multicolumn{2}{c}{ Skewness } \\
\cline { 2 - 8 } & Statistic & Statistic & Statistic & Statistic & Statistic & Statistic & Std. Error \\
\hline $\begin{array}{l}\text { high quality equals to } \\
\text { high price }\end{array}$ & 42 & 1 & 5 & 3.29 & 1.019 & -.326 & .365 \\
Valid N (listwise) & 42 & & & & & & \\
\hline
\end{tabular}

Table-1.2. Descriptive Statistics

\begin{tabular}{lccccccc}
\hline & \multicolumn{1}{c}{} & \multicolumn{2}{c}{ Minimum } & Maximum & Mean & Std. Deviation & \multicolumn{2}{c}{ Skewness } \\
\cline { 2 - 7 } & Statistic & Statistic & Statistic & Statistic & Statistic & Statistic & Std. Error \\
\hline $\begin{array}{l}\text { high quality equals to } \\
\text { high price }\end{array}$ & 42 & 2 & 5 & 4.33 & .786 & -1.312 & .365 \\
Valid N (listwise) & 42 & & & & & & \\
\hline
\end{tabular}

Table-1.3. One-Sample Test

\begin{tabular}{|c|c|c|c|c|c|c|}
\hline & \multicolumn{6}{|c|}{ Test Value $=4$} \\
\hline & \multirow{2}{*}{$\mathrm{t}$} & \multirow{2}{*}{ df } & \multirow{2}{*}{ Sig. (2-tailed) } & \multirow{2}{*}{$\begin{array}{l}\text { Mean } \\
\text { Difference }\end{array}$} & \multicolumn{2}{|c|}{$\begin{array}{c}95 \% \text { Confidence Interval of the } \\
\text { Difference }\end{array}$} \\
\hline & & & & & Lower & Upper \\
\hline $\begin{array}{l}\text { high quality equals to } \\
\text { high price }\end{array}$ & -4.543 & 41 & . 000 & -.714 & -1.03 & -.40 \\
\hline
\end{tabular}

Table-1.4. One-Sample Test

\begin{tabular}{|c|c|c|c|c|c|c|}
\hline & \multicolumn{6}{|c|}{ Test Value $=2$} \\
\hline & \multirow{2}{*}{$\mathrm{t}$} & \multirow{2}{*}{ df } & \multirow{2}{*}{ Sig. (2-tailed) } & \multirow{2}{*}{$\begin{array}{l}\text { Mean } \\
\text { Difference }\end{array}$} & \multicolumn{2}{|c|}{$\begin{array}{l}95 \% \text { Confidence Interval of the } \\
\text { Difference }\end{array}$} \\
\hline & & & & & Lower & Upper \\
\hline $\begin{array}{l}\text { high quality equals to } \\
\text { high price }\end{array}$ & 8.177 & 41 & . 000 & 1.286 & .97 & 1.60 \\
\hline
\end{tabular}

Table-1.5. One-Sample Test

\begin{tabular}{|c|c|c|c|c|c|c|}
\hline & \multicolumn{6}{|c|}{ Test Value $=4$} \\
\hline & \multirow{2}{*}{$\mathrm{t}$} & \multirow{2}{*}{ df } & \multirow{2}{*}{ Sig. (2-tailed) } & \multirow{2}{*}{$\begin{array}{c}\text { Mean } \\
\text { Difference }\end{array}$} & \multicolumn{2}{|c|}{$\begin{array}{l}95 \% \text { Confidence Interval of the } \\
\text { Difference }\end{array}$} \\
\hline & & & & & Lower & Upper \\
\hline $\begin{array}{l}\text { high quality equals to } \\
\text { high price }\end{array}$ & 2.748 & 41 & . 009 & .333 & .09 & .58 \\
\hline
\end{tabular}


Test Value $=2$

\begin{tabular}{|c|c|c|c|c|c|c|}
\hline & \multicolumn{6}{|c|}{ ILd varac - 2} \\
\hline & \multirow{2}{*}{$\mathrm{t}$} & \multirow{2}{*}{ df } & \multirow{2}{*}{ Sig. (2-tailed) } & \multirow{2}{*}{$\begin{array}{l}\text { Mean } \\
\text { Difference }\end{array}$} & \multicolumn{2}{|c|}{$\begin{array}{l}95 \% \text { Confidence Interval of the } \\
\text { Difference }\end{array}$} \\
\hline & & & & & Lower & Upper \\
\hline $\begin{array}{l}\text { high quality equals to } \\
\text { high price }\end{array}$ & 19.237 & 41 & .000 & 2.333 & 2.09 & 2.58 \\
\hline
\end{tabular}

\section{Interpretation}

There is no consistency between high quality equals to high price (V1) and high quality with low price (V2). Participants respond V2 (I need high quality product with low price) more reactive or stronger. One-sample test with test value of 4 (agree) for V2 shows smaller interval of the difference (lower $=.09$ and upper $=.58$ ) compared to V1 (lower $=-1.03$ and upper $=-.40$ ). The mean difference for V2 with test value 4 is .333 smaller than -.714. Participants seem to be more reactive when it comes to the statement: "I need high quality with low price." Combination of "low price and high quality" seems to be attractive compared to "high price and high quality". Statement in V1 is actually similar to statement in $\mathrm{V} 2$, but participants give much favor to $\mathrm{V} 2$.

Consistency Test-2: Group consistency test related with V2 (see Table-2.1 to 2.8). One-sample test (test value $=4$ / agree) to measure difference between 2 (two) groups related with their response to the

statement "What I need is high quality with low price". The groups are Group Choice- 4 ie. those who chose the statement "I prefer medium price with high quality", and Group Choice-7 ie. those who chose the statement "I prefer low price with high quality". From questionnaire tabulation it is shown 19 participants choose Choice- 4 and 23 participants choose Choice-7. The author takes 19 participants from both groups so that it will be equal.

\section{Interpretatio}

See Table-2.1 and 2.2 Group Choice-4 "I prefer medium price with high quality" has shown more on mean value 4 (=agree) to the statement "what I need is high quality with low price". Mean value 3.84 for Group Choice-4 has the same with mean value 4 (=agree). 2-tailed significance test shows .420 (Table-2.3) which is greater than .05. There is no difference between mean value 3.84 and 4 . The rationality of "I prefer medium price with high quality" (Choice-4) inconsistently changed when

\section{Table-2.1. Descriptive Statistics}

\begin{tabular}{lccccccc}
\hline & $\mathbf{N}$ & \multicolumn{2}{c}{ Minimum } & Maximum & Mean & Std. Deviation & \multicolumn{2}{c}{ Skewness } \\
\cline { 2 - 8 } & Statistic & Statistic & Statistic & Statistic & Statistic & Statistic & Std. Error \\
\hline $\begin{array}{l}\text { high quality equals to } \\
\text { high price }\end{array}$ & 42 & 2 & 5 & 4.33 & .786 & -1.312 & .365 \\
Valid N (listwise) & 42 & & & & & & \\
\hline
\end{tabular}

Table-2.2. One-Sample Statistics

\begin{tabular}{lcccc}
\hline & $\mathbf{N}$ & Mean & Std. Deviation & Std. Error Mean \\
\hline V_2 choice_4 & 42 & 4.33 & .786 & .191 \\
\hline
\end{tabular}

Table-2.3. One-Sample Test

\begin{tabular}{|c|c|c|c|c|c|c|}
\hline & \multicolumn{6}{|c|}{ Test Value $=4$} \\
\hline & \multirow{2}{*}{$\mathrm{T}$} & \multirow{2}{*}{ df } & \multirow{2}{*}{ Sig. (2-tailed) } & \multirow{2}{*}{$\begin{array}{l}\text { Mean } \\
\text { Difference }\end{array}$} & \multicolumn{2}{|c|}{$\begin{array}{c}95 \% \text { Confidence Interval of the } \\
\text { Difference }\end{array}$} \\
\hline & & & & & Lower & Upper \\
\hline V_2 choice_4 & -.825 & 18 & .420 & -.158 & -.56 & .24 \\
\hline
\end{tabular}

Table-2.4. One-Sample Statistics

\begin{tabular}{lcccc}
\hline & N & Mean & Std. Deviation & Std. Error Mean \\
\hline V_2 choice_7 & 19 & 4.74 & .452 & .104 \\
\hline
\end{tabular}

Table-2.5. One-Sample Test

\begin{tabular}{|c|c|c|c|c|c|c|}
\hline & \multicolumn{6}{|c|}{ Test Value $=4$} \\
\hline & \multirow{2}{*}{$\mathrm{T}$} & \multirow[t]{2}{*}{ Df } & \multirow{2}{*}{ Sig. (2-tailed) } & \multirow{2}{*}{$\begin{array}{l}\text { Mean } \\
\text { Difference }\end{array}$} & \multicolumn{2}{|c|}{$\begin{array}{l}95 \% \text { Confidence Interval of the } \\
\text { Difference }\end{array}$} \\
\hline & & & & & Lower & Upper \\
\hline V_2 choice_7 & 7.099 & 18 & .000 & .737 & .52 & .95 \\
\hline
\end{tabular}

Table-2.6. Paired Sample Statistics

\begin{tabular}{llcccc}
\hline & & N & Mean & Std. Deviation & Std. Error Mean \\
\hline Pair 1 & V_2 choice_4 & 19 & 3.84 & .834 & .191 \\
& V_2 choice_7 & 19 & 4.74 & .452 & .104 \\
\hline
\end{tabular}

Table-2.7. Paired Sample Correlations

\begin{tabular}{llccc}
\hline & & $\mathrm{N}$ & Correlation & Std. Error Mean \\
\hline Pair 1 & V_2 choice_4 \& & 19 & .178 & .465 \\
& V_2 choice_7 & & & \\
\hline
\end{tabular}

Table-2.8. Paired Sample Test Paired Differences

\begin{tabular}{|c|c|c|c|c|c|c|c|}
\hline \multicolumn{8}{|c|}{ Paired Differences } \\
\hline \multirow[t]{2}{*}{ Mean } & \multirow[t]{2}{*}{$\begin{array}{c}\text { Std. } \\
\text { Deviation }\end{array}$} & \multirow[t]{2}{*}{$\begin{array}{l}\text { Std. Error } \\
\text { Mean }\end{array}$} & \multicolumn{2}{|c|}{$\begin{array}{l}95 \% \text { Confidence } \\
\text { Interval of the } \\
\text { Difference }\end{array}$} & \multirow[t]{2}{*}{$\mathrm{T}$} & \multirow[t]{2}{*}{ Df } & \multirow{2}{*}{$\begin{array}{c}\text { Sig. } \\
\text { (2-tailed) }\end{array}$} \\
\hline & & & Lower & Upper & & & \\
\hline 7.099 & 18 & .737 & .52 & .95 & -4.456 & 18 & .000 \\
\hline
\end{tabular}


it comes with "what I need is high quality with low price" (V2).

See Table-2.4 and 2.5. Those belong to Group Choice-7 "I prefer low price with high quality" have mean value 4.74 . With one-sample test it has shown that mean value 4.74 is not the same with 4 (=agree). 2-tailed significance test shows .000 (Table-2.5) which is smaller than .01. The mean value tends to be closer to 5 (=strongly agree). In other words, those who choose Choice-7 are very consistent with the statement "what I need is high quality with low price" (V2). Table-2.6 and 2.7 shows that there is no correlation between Choice-4 and Choice-7 related with the statemen

Table-3.1. Descriptive Statistics

\begin{tabular}{lccccc}
\hline & $\mathbf{N}$ & Minimum & Maximum & Mean & Std. Deviation \\
\hline I need high quality with low price & 42 & 2 & 5 & 4.33 & .786 \\
Price is more important than product quality & 42 & 1 & 5 & 1.74 & .798 \\
Valid N (listwise) & 42 & & & & \\
\hline
\end{tabular}

Valid N (listwise)

Table-3.2. One-Sample Statistics

\begin{tabular}{lcccc}
\hline & $\mathbf{N}$ & Mean & Std. Deviation & Std. Error Mean \\
\hline $\begin{array}{l}\text { Price is more important } \\
\text { than product quality }\end{array}$ & 42 & 1.74 & .798 & .123 \\
\hline
\end{tabular}
than product quality

Table-3.3. One-Sample Test

\begin{tabular}{|c|c|c|c|c|c|c|}
\hline & \multicolumn{6}{|c|}{ Test Value $=2$} \\
\hline & \multirow[t]{2}{*}{$\mathrm{t}$} & \multirow{2}{*}{ df } & \multirow{2}{*}{ Sig. (2-tailed) } & \multirow{2}{*}{$\begin{array}{c}\text { Mean } \\
\text { Difference }\end{array}$} & \multicolumn{2}{|c|}{$\begin{array}{l}95 \% \text { Confidence Interva } \\
\text { of the Difference }\end{array}$} \\
\hline & & & & & Lower & Upper \\
\hline $\begin{array}{l}\text { Price is more important } \\
\text { than product quality }\end{array}$ & -2.127 & 41 & .040 & -.262 & -.51 & -.01 \\
\hline
\end{tabular}

Table-3.4. One-Sample Statistics

\begin{tabular}{lcccc}
\hline & $\mathrm{N}$ & Mean & Std. Deviation & Std. Error Mean \\
\hline $\begin{array}{l}\text { I need high quality with } \\
\text { low price }\end{array}$ & 42 & 4.33 & .786 & .121
\end{tabular}

The significance value .465 (Table 2.7) is greater than 05 . The between V2_Choice-4 and V2_Choice-7 can not be is .000 which is smaller than .001 . It means that there is a significant difference between statement (V2) but they can not be categorized

Consistency Test-3: Consistency test between V2 and V3 (see Table-3.1 to 3.5).
Table-3.5. One-Sample Test

Table-3.1 to 3.3 shows mean value of V3 (Price is more important than product) is 1.74 which is also 2 (=disagree). The 2-tailed significance test for value 2 is .040 which is greater than .01 . The hypothesis that there is no difference between mean value of 1.74 and 2 can not be rejected. Table-3.4 to 3.5 shows mean value of V2 (What I need is high quality with low price) is 4.33 which is 4 (=agree). The 2-tailed significance test for value 4 is .009 which is greater than .001 . It means that the hypothesis that there is no difference between mean value of 4.33 and 4 can not be rejected. The

result shows that participants are not consistent related with V3 (Price is more important than product) and V2 (What I need is high quality with low price). According to them price is not more important than product quality (see Table-3.1 to 3.3), while at the same time, they need high quality with low price (see Table-3.4 to 3.5). If they think that high quality product is more important then it should follow with the price.

Consistency Test-4: Consistency test between V and V4 (see Table-4.1 to 4.5)

Table-4.1. Descriptive Statistics

\begin{tabular}{lccccc}
\hline & N & Minimum & Maximum & Mean & Std. Deviation \\
\hline $\begin{array}{l}\text { Price always has connection } \\
\text { with product quality }\end{array}$ & 42 & 3 & 5 & 4.14 & .718 \\
\begin{tabular}{l} 
Valid N (listwise) \\
\hline
\end{tabular} & 42 & & & & \\
\hline
\end{tabular}

Table-4.2. Descriptive Statistics

\begin{tabular}{lccc}
\hline & Mean & Std. Deviation & $\mathrm{N}$ \\
\hline $\begin{array}{l}\text { High quality is always } \\
\text { followed by high price }\end{array}$ & 3.29 & 1.019 & 42 \\
$\begin{array}{l}\text { Price always has connection } \\
\text { with product quality }\end{array}$ & 4.14 & .718 & 42 \\
\hline
\end{tabular}

Table-4.3. One-Sample Test

\begin{tabular}{lcccccc}
\hline & \multicolumn{6}{c}{ Test Value $=3$} \\
\cline { 2 - 4 } & & $\mathrm{t}$ & $\mathrm{df}$ & Sig. (2-tailed) & $\begin{array}{c}\text { Mean } \\
\text { Difference }\end{array}$ & \multicolumn{2}{c}{$\begin{array}{c}95 \% \text { Confidence Interval } \\
\text { of the Difference }\end{array}$} \\
\cline { 6 - 8 } & & & & & Lower & Upper \\
\hline $\begin{array}{l}\text { High quality is always } \\
\text { followed by high price }\end{array}$ & 1.817 & 41 & .077 & .286 & -.03 & .60 \\
\hline
\end{tabular}




\begin{tabular}{lcccccc}
\hline & \multicolumn{6}{c}{ Test Value $=4$} \\
\cline { 2 - 5 } & & $\mathrm{t}$ & $\mathrm{df}$ & Sig. (2-tailed) & $\begin{array}{c}\text { Mean } \\
\text { Difference }\end{array}$ & \multicolumn{2}{c}{$\begin{array}{c}\text { 95\% Confidence Interval } \\
\text { of the Difference }\end{array}$} \\
\cline { 6 - 8 } & & & & & Lower & Upper \\
\hline $\begin{array}{l}\text { Price always has } \\
\text { connection with product } \\
\text { quality }\end{array}$ & 1.289 & 41 & .205 & .143 & -.08 & .37 \\
\hline
\end{tabular}

Table-4.5. Correlations

\begin{tabular}{llcc}
\hline & & $\begin{array}{c}\text { High quality is always } \\
\text { followed by high price }\end{array}$ & $\begin{array}{c}\text { Price always has connection } \\
\text { with product quality }\end{array}$ \\
\hline High quality is always & Pearson Correlation & 1 & .143 \\
followed by high price & Sig. (2-tailed) & & .367 \\
& $\mathrm{~N}$ & 42 & 42 \\
\hline Price always has connection & Pearson Correlation & .143 & 1 \\
with product quality & Sig. (2-tailed) & .367 & \\
& $\mathrm{~N}$ & 42 & 42 \\
\hline
\end{tabular}

\section{Interpretation}

Mean value of V1 (High quality is always followed by high price) is 3.29 which is also 3 (=uncertain). The value of 2-tailed significance test for 3 is .077 which is greater than .05 . It can not reject null hypothesis. It means there is no difference between 3.29 and 3. While mean value of V4 (Price always has connection with product quality) is 4.14 . The value of 2-tailed significance test for 4 (=agree) is .205 which is also greater than .05 . There is no difference between 4.14 and 4 . The participants are uncertain about the statement "High quality is always followed by high price". This uncertainty may be caused by their experience to find high quality product with relatively low price in the market. Therefore, they may have the idea that high quality product is not always followed by high price.

Phase-2

Data used for Phase-2 are taken from Questionnaire-2. Participants were assigned to respond two challenging and disturbing statements - "If you suspiciously find out a product as very cheap, what do you mean by it?" (Statement-1) and "If you say that a product is too expensive, what do you mean by it?" (Statement-2). Statement-1 has 4 (four) choices of response: I like the product (V1); I can buy the product if I want (2); I don't want to buy it because of low quality (V3); It's impossible. I'm in doubt of it. So, I don't want to buy it (V4). While Statement-2 has 4 (four) choices of response: I don't have enough money to buy (V5); The product quality is "too high" for me (V6); I agree that the product quality is very high, but I don't need that too much for product quality (V7); The product quality is considered as "low quality" (V8).

There are 37 participants participated in Phase-2 . They are the same students who took Phase-1. The average mean value from two statements is 3 (=uncertain) which means most of the choosing 5 (=strongly agree) or 1 (=strongly disagree), or even in choosing 4 (=agree) or 2 (=disagree). Choice of 3 (=uncertain) seems participants seem to be lack of confidence in

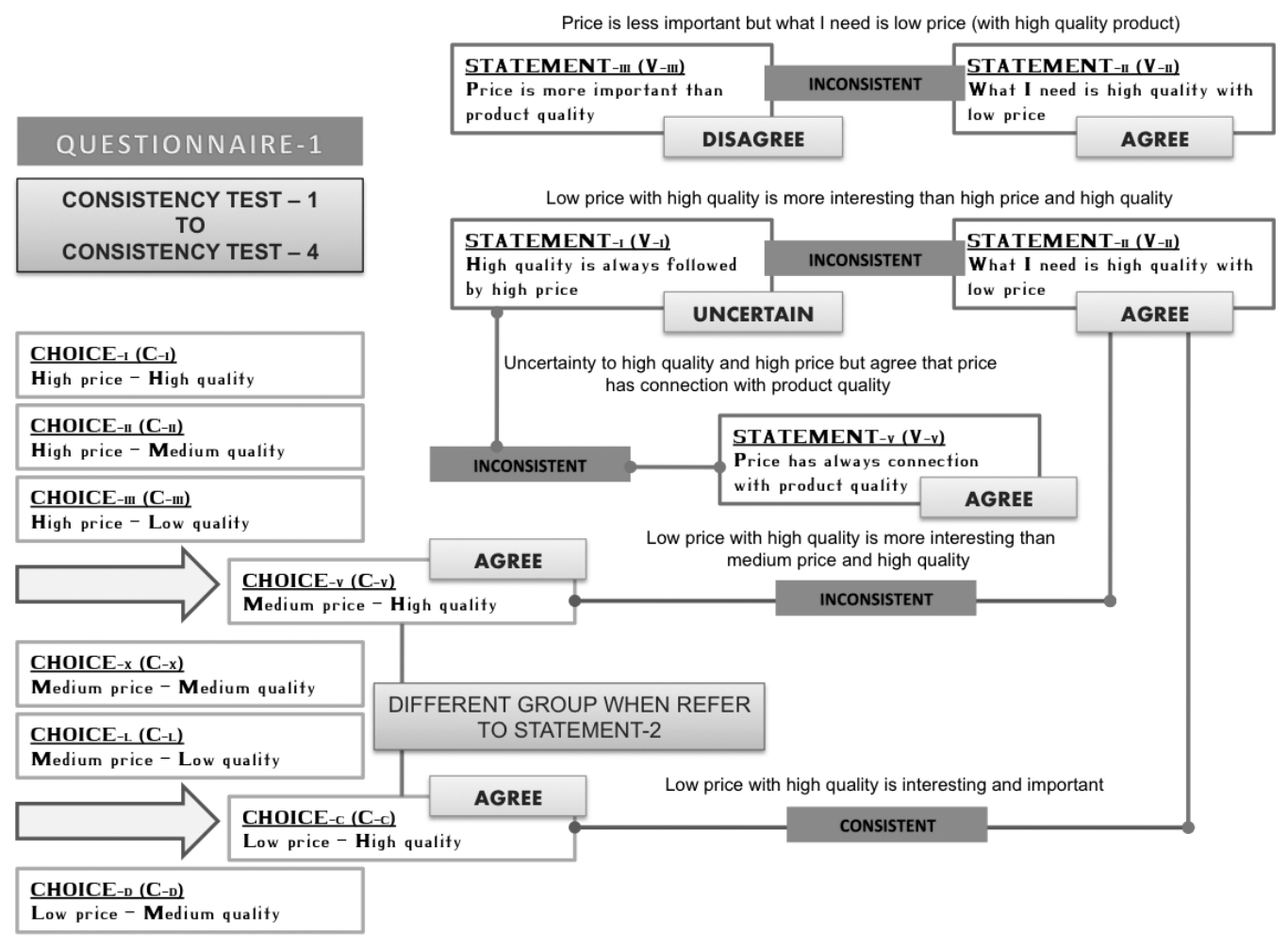

Exhibit 6: Result from Phase - 1

to be more safe rather than trying to challenge by getting into deeper understanding and make absolute response "agree" or "disagree".

The author randomly chooses four participants who are able to express his/her responses confidently using the absolute value 5 (=totally agree) or 1 (=totally disagree). Their initials are CH (Female), DM (Female), SP (Female), and PP (Male).

$\mathrm{CH}$ gives absolute response of 5 (=strongly agree) for "I can buy the product if I want". This response is used to answer "If you suspiciously find out a product as very cheap, what do you mean by it?" Even in the condition that product is "suspiciously very cheap" $\mathrm{CH}$ responds strongly with "I can buy the product if I want". Her rationality leads her to the "very cheap product" instead of considering the element of "suspicious". CH and DM give absolute response of 5 (=strongly agree) for "I don't have enough money to buy" and "The product quality is too high for me" to answer "If you say that a product is too expensive, what do you mean by it?" The meaning of "too expensive" is about buying power and unexpected product quality. While DM strongly agrees with "I don't want to buy it because of low quality" to response "suspiciously very cheap" product. SP strongly agrees that "too expensive" means "the product quality is too high" and she doesn't need it. While PP strongly disagrees with "I can buy the product if I want" in response to "suspiciously very cheap" product.

Phase-3

In Phase-3 the author uses Narrative Analysis. It involves reading and interpretating participants' narratives or compositions as suggested by Colaizzi (1978) in Goulding (2004). There are two participants who are selected as they are appointed by the group as the best students in academic performance at the Marketing Department. This is made to meet with assumption that they are considered as competent and rational enough to make a decision specially related with perceived 


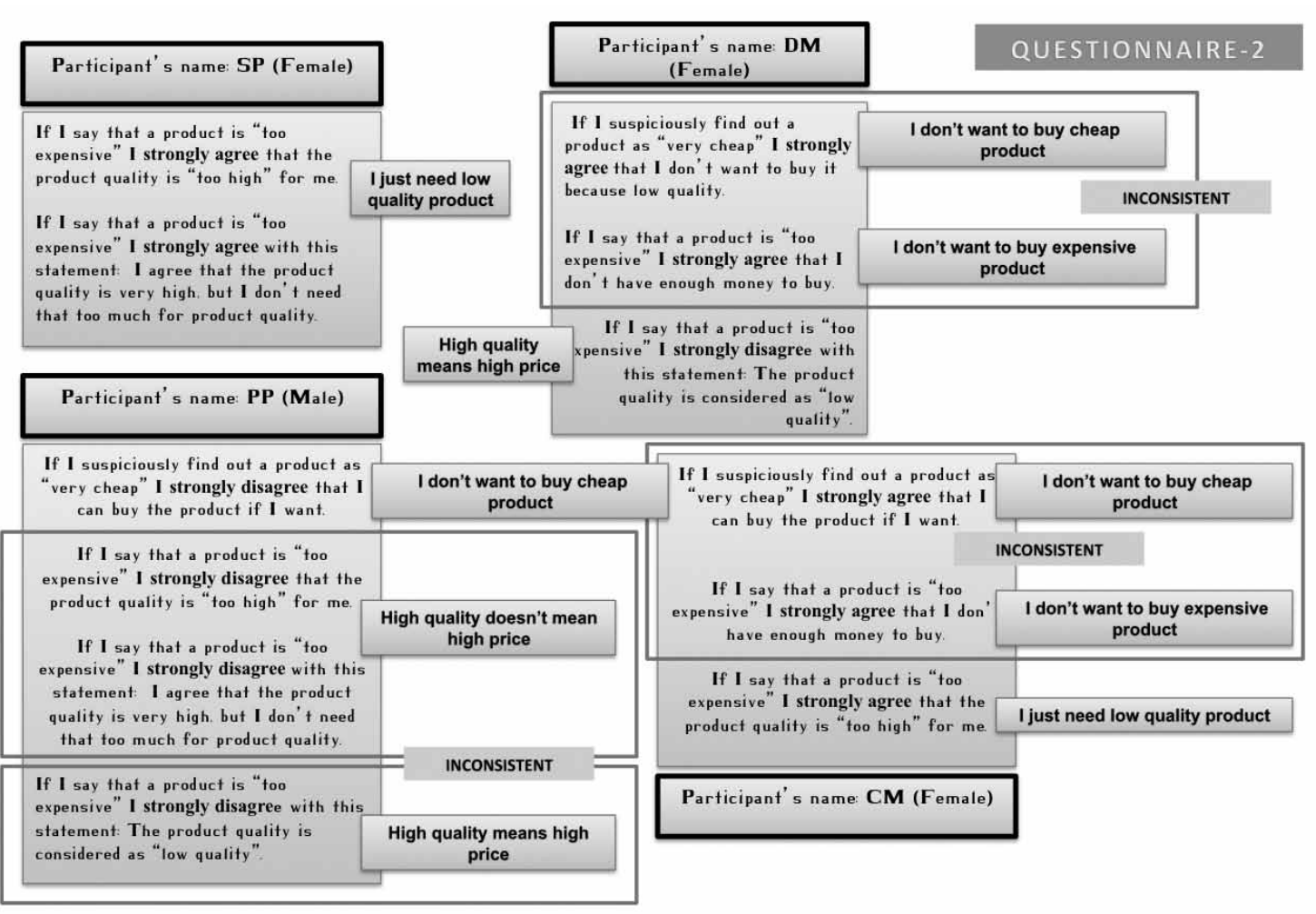

Exhibit 7: Result from Phase - 2

price-quality. Their initials are LM (male) and SC (female). They are required to make two compositions. First composition is entitled "My Story of Best Offer Product", while the second one is "My Story of Disappointed Product". As part of interpretation process the author identifies Feeling, Main Statement, Meaning and Theme. Framework of the interpretation is around the issue of perceived price-quality.

\section{LM_My Story of Best Offer Product}

Feeling: supportive, happy, proud, recommending

Main Statement and Meaning :

"I passed by an advertisement in the newspaper from a mobile network company called SC that offers post paid plans with free mobile phones depending on which category you apply in. I chose the Plan 350 offer. Plan say that $S C$ is the cheapest when it comes to rates and charges mainly because of their unlimited offers and perks." (= I use the same product as many people do.)

Theme:

Free product and social value are really attractive for me

\section{LM_My Story of Disappointed Product}

Feeling: dissatisfied, disappointed, sad

Main Statement and Meaning:

"I happen to pass by a local grocery store in the city and upon checking the hygiene section, what captured my attention is the new product called Close Up White Now. It's a toothpaste that instantly whitens your teeth after you brush. It costs a more or less 65 pesos since I forgot how much it really costs. I was amazed by what it says outside of the box. I said in my mind that I should try this product because of all the benefits and values I can gain after I try this one. I was excited to try this product because it says that Close up White Now is the newest variant of Close Up." ( $=\mathrm{I}$ believe that the advertisement is necessary and true.)

When I reached home, after we had lunch, I want to test the product. I went straight to the sink and brushed my teeth really hard and it took me more or less 2 minutes to brush. I like the minty scent while I was brushing. And the final judgment came, when I went up into the mirror just above the sink, I was surprised and disappointed that there was no effect that happened. ( $=$ I need to know the exact result as soon as I reach home.)

"Honestly, I was pissed and disappointed of the product. Why do they overpromise a certain product that it gives a lot of benefits and values when in fact all it can even do is just to clean your teeth? Why persuade consumers to the extent that they go crazy about it and in the end they will just be disappointed? Why don't they think that if they overpromise, and the consumers get disappointed, they will just lose value from customers?" (= Advertisement should bring truth.)

Theme:

Amazing advertisement and emotional response!

3. SC_My Story of Best Offer Product

Feeling: happy, proud

Main Statement and Meaning:

"My mother told me that I should buy a moisturizer to help bring back the moisture of my skin. As we were choosing and buying things, I stopped for a moment because saw this very beautiful and eye catching moisturizing lotion. It was a "Myra-E Hand and Body Lotion". I suddenly remembered their commercial that said that it helps bring back the moisture of damaged skin. I examined very clearly the moisturizing lotion and told my mother to buy it because it was on sale and it was very cheap but I can no longer remember the price. We bought the product at home." (= Previous commercial messages and low price attract me.)

"I think the "Myra-E Hand and Body Lotion" was a best seller because during those times, I was in need of a moisturizing lotion and that was the only lotion in the mall that had everything that I was looking for. The other lotions were good too but they did not contain the ingredients I was looking for. The moisturizing lotion was the best seller because the packaging was very good and very eye friendly. I tried the lotion at home and it actually worked. The lotion had in its cover 
that it can help bring back the moisture of your skin in two weeks and it actually worked. My skin was back to its normal moisture with the help of the "Myra-E Hand and Body Lotion". I tried the lotion twice a day and it was very convenient." (= I have no choice and this product is convincing and looks nice.)

"My comment to the "Myra-E Hand and Body Lotion" is that, it helped me bring back the moisture of my skin in a less expensive manner. The product is very good and the market strategy being used is very effective. The product did not just satisfy my need but it also helped me save my money." (= It really saves my money.)

Theme:

It is just the price!

4. SC_My Story of Disappointed Product

Feeling: sad, acceptable

Main Statement and Meaning:

"I personally had a bad experience on a disappointing product. I decided to change my shampoo due to the weather because it is very hot in the Philippines I was having a lot of dandruffs. I saw this commercial on the television about the "Vaseline Natural 2 in 1 Anti-Dandruff with Lemon Shampoo and Conditioner". The shampoo was very pleasing because they actually have shown people who have already used their product and they were satisfied. So the day my mother and I went to the mall, I bought the shampoo because my dandruffs were unbearable. As I went home I placed the shampoo inside the bathroom so that I can use it." (= I want to be like them.)

"I was very disappointed with the "Vaseline Natural 2 in 1 Anti-Dandruff with Lemon Shampoo and Conditioner" because instead of removing my dandruffs it even increased it.
My head was full of dandruffs and there was even a point where I was about to cry because I cannot bear my dandruffs anymore. I immediately threw away the "Vaseline Natural 2 in 1 Anti-Dandruff with Lemon Shampoo and Conditioner" and decided never to use any Vaseline products ever again. Aside from the fact that the shampoo did not work and made things worse, it was also very expensive. I learned my lessons based from the shampoo and promised myself not to purchase anything from the company." (= I'm wrong. It's expensive.)

\section{Theme:}

It's expensive when product fails to meet my expectation.

\section{Phase-4}

In Phase-4 participants were given two Situations in which they are challenged by perceived pricebenefit. Each situations consists two statements which contain the idea of price (Statement-1) and benefit (Statement-2). Situation-1 is dealing with high price and more benefit, while Situation-2 describes a stituation of low price and less benefit (Exhibit-11). At the end they are required to make choice. Choice-A: more convenience and timesaved store with high-priced product. Choice-B: less convenience and less time-saved store with low-priced product. Results show that participants tend to favor Situation-1 and Choice-A. They agree that price should have connection with benefit ie. expensive price for high benefit and cheap price for low benefit. However, results reveal paired differences between Statement-1 and Statement-2 with two-tailed significance less than 0.01 (Exhibit-12).

Results from Phase-1 shows some patterns of inconsistent response that is mostly favorable to low price. The statement of "low price and high quality" seems to be favorite and very attractive as it is chosen by most of the participants. This is relevant with Conceptual Model - 1 (Exhibit-1)

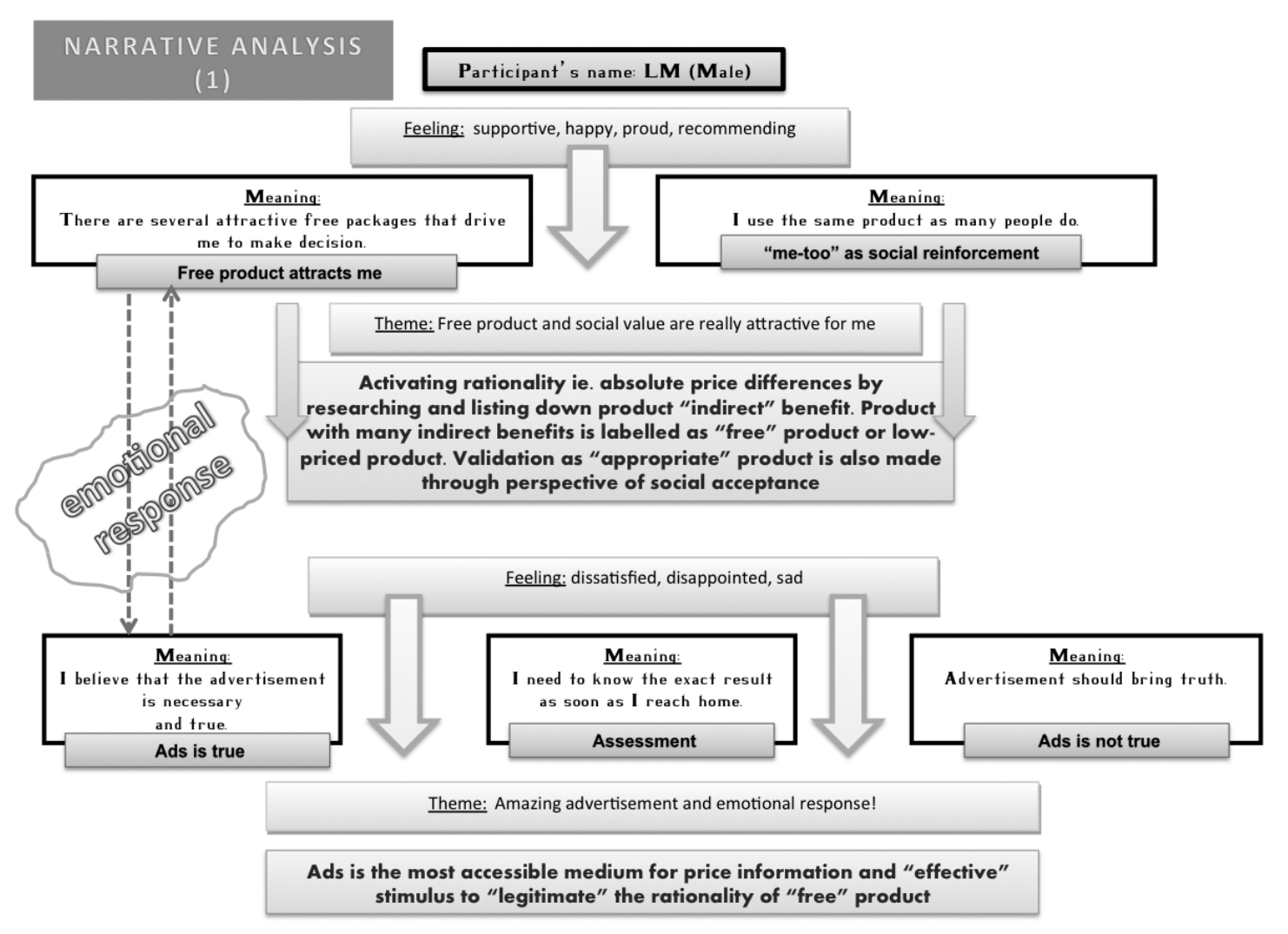

Exhibit 8: Result from Phase-3: Narrative Analysis (1)

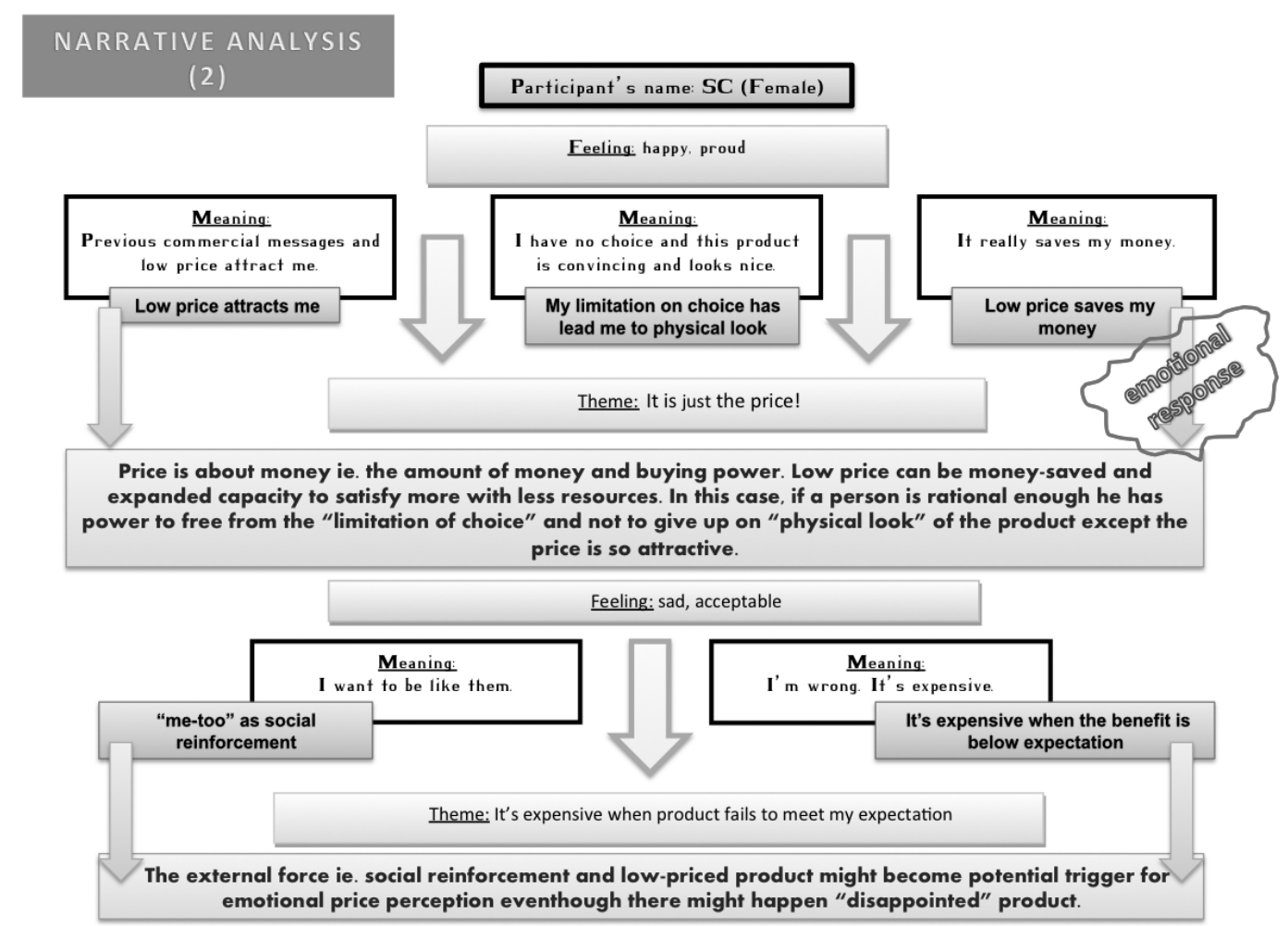

Exhibit 9: Result from Phase-3: Narrative Analysis (2) 


\section{SITUATION-1}

Vinnie is a construction worker who makes $\$ 12$ per hour. Although he could work overtime on Saturday at $\$ 18$ per hour, he takes off two consecutive Saturdays to go fishing. Vinnie is a heavy drinker of Diet Pepsi. On the morning of his first Saturday off, he walks two blocks to a convenience food store to purchase a 12-pack for his fishing trip. The price is $\$ 5$ plus 5 percent sales. Vinnie complains about the high price and is told by the clerk, "I don't set the prices. Take it or leave, Jack!" Vinnie is more than a little upset, but he pays the money because he's in a rush to get to the lake. He vows to himself never to get ripped off like this again. He walks home. The whole trip has taken 10 minutes.

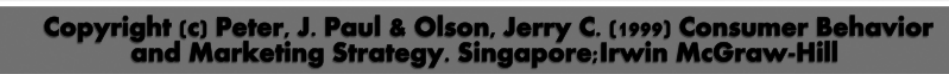

\section{SITUATION-2}

On the next Saturday, Vinnie again needs a 12pack of Diet Pepsi for his fishing trip. Remembering his previous experience at the convenience store, he decides to get in his car and drive 6 miles to the discount supermarket. He is pleasantly surprised that Diet Pepsi is on sale for $\$ 2.99$ a dozen plus tax. Although the store is a bit crowded and it takes him a while to get through the checkout, he drives home feeling good about the purchase and the money he saved. This shopping trip takes 45 minutes.
GIVEN YOUR CONDITION RIGHT NOW, WHICH ONE DO YOU CHOOSE?

CHOICE-A

MORE CONVENIENCE AND TIMESAVED STORE BUT HIGH-PRICED PRODUCT

\section{CHOICE-B}

\section{LESS CONVENIENCE AND LESS} TIME-SAVED STORE BUT

\section{LOW-PRICED PRODUCT}




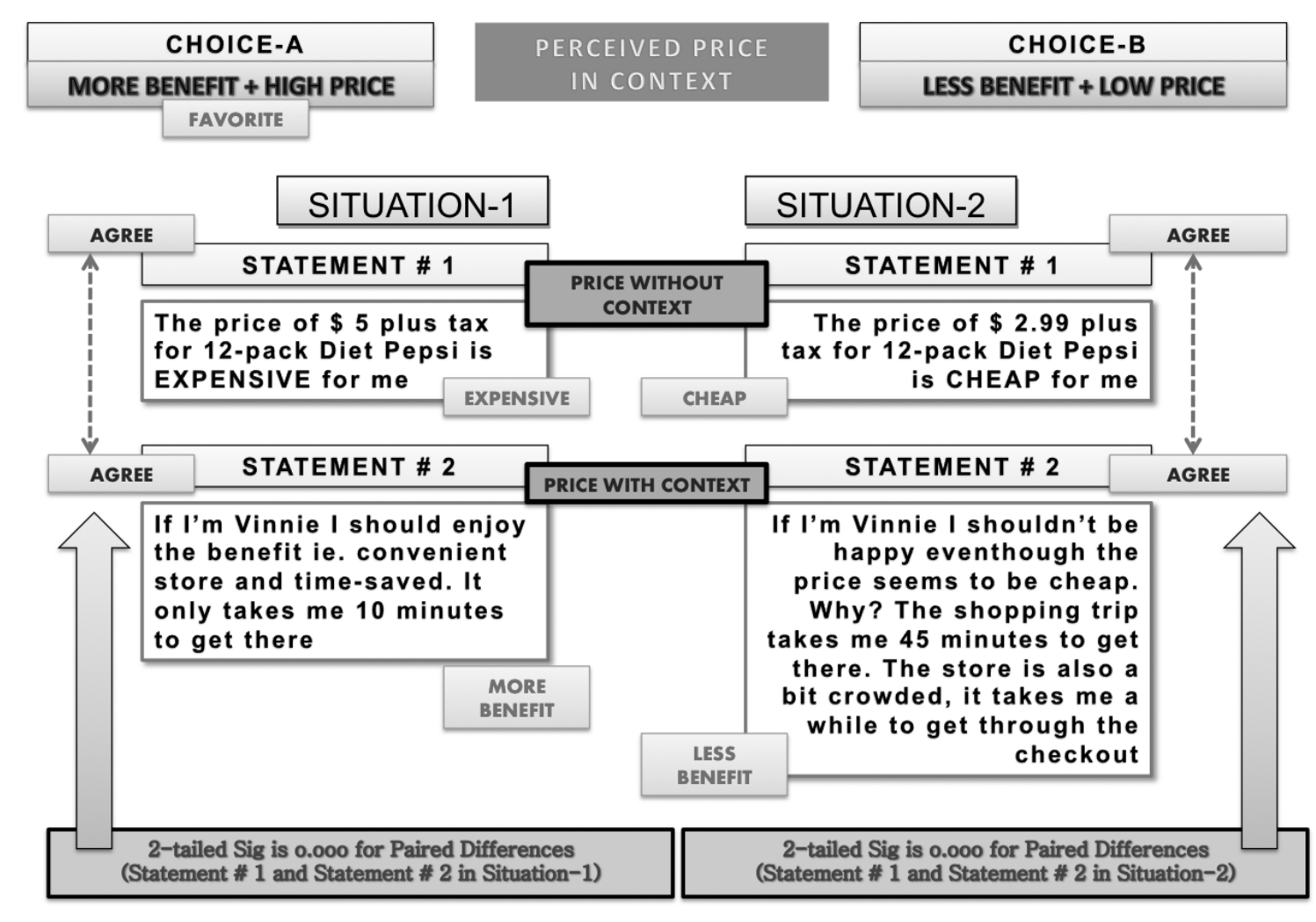

Exhibit 12: Result from Phase-4

that consumers tend to make more effort to save a certain absolute amount when the good's price is lower, because relative to the good's price the savings seem larger. Consumers use their absolute and relative thinking as they are aware with their decision. They measure price with time and effort for more savings motive.

Some choose "medium price and high quality" (Phase-1) which senses more realistic though there is still expectation that price could be more reasonable and lower in relevance with Theory-4 (Exhibit-4). As compared to theory of consumer perception of price unfairness (Exhibit-3) the choice of "medium price and high quality" may indicate participants' objection with high price. However, the two groups namely Group Choice- 4 (medium price and high quality) and Group Choice-7 (low price and high quality) give much favor on "what I need is high quality with low price" (see Phase-1). It is not about high quality but low price. They agree that "price always has connection with product quality" (mean value $=$ 4.14). Price, specially low price, is more interesting than product itself. From the viewpoint of Theory-2 - a free product (Exhibit-2), participants' tendency to favor lower price might indicate lack of information. If lower price resembles with free product there will be such a great sacrifice for the participants to give up all hope of appearing dignified. This could be a new interesting area for further research ie. between perceived price and human dignity.

Table-4.1 to Table-4.5 (see Phase-1) show participants uncertainty about the statement "high quality is always followed by high price" (V1) compared to "price always has connection with product quality" (V4). Mean value of V1 is 3.29 (which is significantly $3=$ uncertain) while mean value of $\mathrm{V} 4$ is 4.14 (which is significantly $4=$ agree). $\mathrm{V} 1$ and $\mathrm{V} 4$ are drawn from the same main idea ie. "one direction" of relationship between price and product quality. High price means high product quality, low price means low product quality. This uncertainty might be caused by their experience to find high quality product with relatively low price in the market. Theory-4 (Exhibit-4) states that price is an important measure of quality as perceived by consumers. For the seller, setting prices higher than rivals is probable in the markets in which the buyer is impressed with the importance of quality but has difficulty in identifying it. From this perspective it seems that there is a "great temptation" to favor "what I need is high quality with low price" (V2).

From Phase-2 the author is able to find those (PP, $\mathrm{SP}, \mathrm{CH}$ and $\mathrm{DM})$ who have strong character to give absolute or extreme response of 1 (=strongly disagree) and 5 (=strongly agree). The controlled element of "suspiciously very cheap" price is responded differently by them. The absolute or extreme response to that element (either 1 or 5) indicates possible consideration that lower price is still powerful and attractive eventhough the element of "suspicious" is present. Referring to Theory-3 (Exhibit-3) the reactive or emotional decision is the results of multiple motivations, but in particular the motives of sociability and selfexpression. The absolute or extreme response could be a pressure from social eg. "suspiciously very cheap" is a common term for "negativity" so that the response will be 1 (=strongly disagree), or a just a "best offer" product supported by relative thinking (see Theory-1) so that the possible response is 5 (=strongly agree). Self-expression reflects participants' strong identity to express agree or disagree.

Interpretation resulted from narratives analysis of LM and SC (Phase-3) has shown that external reference is still very relevant and effective stimulus to value perceived price-quality. This corresponds to Theory-4 (Exhibit-4). Perceived price-quality is mainly caused by hidden pressure of certain values such as identity and money. Price may have more than one meaning to a consumer (Exhibit-4). SC's experience on wrong buying has lead her to define it as expensive price or high price with low quality (Phase-3) which corresponds to Theory-3 (Exhibit-3 and Exhibit-5 Area-2). While low price with attribute "free" is still favorite and attractive, on the contrary, high price or expensive is also an image of "wrong product" (see also Azar 2009, Anderson 2009). Product's physical appearance is easily used to value quality specially when there is no other rivals.

Findings from Phase-1 and Phase-4 show contradiction in participants' reponses on "what I need is high quality with low price" (Phase-1) and "I choose expensive price with more benefit" (Phase-4 Exhibition-11). This viewpoint may show in need of specific situation regarding with perceived price-quality relationship. There should be quite understandable the difference between price without context and price with context (Exhibit-12). Paired differences between Statement-1 and Statement-2 with two-tailed significance less than 0.01 (Phase-4 Exhibit-12) shows that price is sometimes perceived as just a number without context. The other possibility is that participants are just having difficulty to reach proportional understanding between price and benefit.

\section{MANAGERIAL IMPLICATIONS}

Price and pricing are two things which are highly relevant in mentioning customers' expectation on product benefit. Hence, product quality should be designed to meet with the benefit as expected by customers. It is a matter of firms' creativity to have constant and informative communicatio with their market through various medium. For instance, advertisements can be effective tool to educate market on product's benefit and its pricing policy. Consequently, advertisements should be validated as the source of truth in perceived pricequality relationship context. 
Both consistency and inconsistency found in consumers' responses on price and quality offer invaluable insights for marketer. Consistency refers to think coherently which is the ability to value proportional between price and benefit. Consumers categorized in this area may have in-elastic demand as they can easily identify the relationship between price and benefit namely higher price for more benefit or high quality and lower price for less benefit or low quality. They are more product-oriented. On the contrary, inconsistency refers to think incoherently. Consumers in this category are price sensitive or price-oriented. They tend to speculate low-priced products with expectation for higher benefit or quality.

Facts of consistency and inconsistency in consumers' responses may have implication that firms should create an environment offering alternativity in prices. In other words, it is necessary that prices should be appropriately applied to specific benefits even in the context of relative price differences. Differences in price should be relevant with differences in product quality. Some segments who are very critical on prices can potentially lead into bad campaign toward the product. Meaning to say there should be a new mechanism to educate market. It is not just about price perception (price without context) but price integrated with benefit (price with context).

\section{CONCLUSION}

Rationalization on participants' responses could be first step to find out dynamics of perceived price-quality. It is reasonable enough to mention that price can effectively play emotion of the market. And, it is about perceived price-quality. Some segments show much favor on low-priced product which may be reality the coming era of new consumers. They are more educated, critical to the price unfairness, and highly expected on product benefit and quality. The linearity of high price with high quality may need some revision. Firms have to work hard to convince market that low price with high quality product is possible without sacrificing product's image.

The author suggest for further in-depth empirical research to achieve more holistic understanding on perceived price-quality.
Monroe, Kent B. and Angela Y. Lee (1999). Remembering Versus Knowing: Issues in Buyers' Processing of Price Information Journal of the Academy of Marketing Science. Vol. 27. No. 2 pp. 207-225

Pace, Elizabeth (2009). The $X$ and $Y$ of Buy. Tennessee: Thomas Nelson Inc.

Robin, Vicki \& Dominguez, Joe (2008). Your money or your life. London: Penguin Books Ltd.

Smith, J. Walker \& Clurman, Ann (1997). Rocking the Ages. New York: Harper Business

\section{REFERENCE}

\section{Anderson, Chris (2009). Free: The future of a radical price.Hyperion: New York}

Azar, Ofer $\mathrm{H}(2009)$. Do consumers make too much effort to save on cheap items and too little to save on expensive items? Experimental results and implications for business strategy. MPRA Paper No. 20962. Posted 25 Feb. 2010/05:46

Baker, Tim \& Roth, Steven (2012). Introducing Irrationality. The Pricing Institute www.thepricinginstitute.com

Bedeian, Arthur G. (1971). Consumer Perception of Price as an Indicator of Product Quality. MSU Business Topic

Bolton, Lisa E; Warlop, Luk and Alba, Joseph W. (2003). Perception of Price (Un)Fairness. Journal of Consumer Research Inc. Vol. 29 March 2003

Berg, Bruce L. (2001). Qualitative Research Methods for the Social Sciences. Boston: Allyn \& Bacon

Carson, David; Gilmore, Audrey; Perry, Chad and Gronhaug, Kjell (2001). Qualitative Marketing Research. London: Sage Publication

Cooper, Donald R. \& Schindler, Pamela S. (2006). Marketing Research. New York: McGraw-Hill Irwin

Goodman, Linda and Helin, Michelle (2009). Why Customers really Buy: Uncovering the emotional triggers that drive sales. New Jersey: Career Press

Goulding, Christina (2004). Grounded theory, ethnography and phenomenology: A comparative analysis of three qualitative European Journal of Marketing Vol. 39 №.3/4, 2005 pp. 294-308

Kotler, Philip \& Keller, Kevin Lane (2009). Marketing Management 13th Edition. Pearson Education South Asia Pte. Ltd. : Singapore 